\title{
PROJETOS DE VIDA DOS DISCENTES DO CEEP- POLO SANTO AMARO
}

\author{
Lúcia Helena dos Reis de Assis Santos ${ }^{1}$
}

\begin{abstract}
RESUMO
O presente artigo tem como objetivo apresentar os Projetos de Vida com foco nas perspectivas profissionais dos discentes do Ensino Médio do Centro Estadual de Educação Profissional em Turismo do Leste Baiano - CEEP, na cidade de Santo Amaro. Para isso foi realizada uma pesquisa bibliográfica e aplicou-se uma técnica em pesquisa educacional denominada Grupo Focal, onde há uma entrevista coletiva com um pequeno grupo de alunos que ordenadamente expõe suas opiniões a partir de perguntas e uma organicidade direcionada. Nas partes que compõem o trabalho estão contemplados os conceitos a luz de alguns autores a cerca da técnica aplicada; os procedimentos utilizados para a execução da técnica bem como os resultados dessa aplicação e os subtítulos que estão relacionados às perguntas realizadas aos alunos.
\end{abstract}

\section{Palavras- CHAVE: Projetos de Vida. Ensino Médio Técnico Profissionalizante. Educação.}

\section{ABSTRACT}

This article aims to present the Life Projects focused on the professional perspectives of the high school students of the State Center of Professional Education in Tourism of Eastern Bahia - CEEP, in the city of Santo Amaro. For this, a bibliographical research was carried out and a technique was applied in educational research denominated Focal Group, where there is a collective interview with a small group of students that neatly exposes their opinions from questions and a directed organicity. In the parts that compose the work are contemplated the concepts in the light of some authors about the technique applied; the procedures used to perform the technique as well as the results of this application and the subtitles that are related to the questions asked the students.

KEY WORDS: Life Projects. High School Vocational Technical. Education.

\section{INTRODUÇÃO}

A elaboração de um trabalho de investigação garante a eficácia quando permeia a necessidade de detectar quais as dificuldades e os entraves existentes que impedem uma evolução dentro de um cenário perceptível aos olhos daqueles que vivem o dia a dia de um

\footnotetext{
${ }^{1}$ Graduada em Matemática pela Universidade Jorge Amado - UNIJORGE. Especialista em Educação Matemática, Gestão Educacional e Planejamento Educacional. Mestra em Ciências da Educação pela Faculdade Interamericana de Ciências Sociais - FICS Professora das Redes Estadual e Municipal de Ensino.Email: lucialenassis@hotmail.com.
} 
ambiente escolar, e se depara com a necessidade de melhor entender o que esses jovens nessa final etapa da educação básica, pensam e quais seus anseios diante do quadro educacional observado e comentado em diversos momentos no fazer pedagógico pelos professores, tão pouco interesse na Escola durante as aulas, considerando que nessa etapa pensa-se que o indivíduo já despertou de maneira pertinente para seu planejamento futuro, ou seja, projetou a sua vida profissional, definindo perspectivas e com responsabilidade atendendo as programações e correspondendo positivamente com efetividade as atividades previstas para seu nível de ensino.

Entendo que os resultados servirão de avaliação nos trabalhos pedagógicos, cada subtítulo a partir do segundo foi a presentado para os alunos em forma de pergunta, na tentativa de buscar alternativas na iminência também de que uma parte da responsabilidade da falta de êxito pode estar em diversos pontos dentro da escola ou fora dela, e a partir dessa investigação teremos subsídios necessários, talvez, não em sua totalidade, capaz de sanar as deficiências e as incertezas que circundam parte desse público que precisa de orientação familiar consistente, bem como orientação escolar dando prosseguimento aos ensinamentos efetivos que ocorrem ou deveriam ocorrer no ambiente familiar.

\section{GRUPO FOCAL- UMA TÉCNICA INVESTIGATIVA}

Para Caplan (1990), os grupos focais são "pequenos grupos de pessoas reunidos para avaliar conceitos ou identificar problemas", constituindo-se em uma ferramenta comum usada em pesquisas de marketing para determinar as reações dos consumidores a novos produtos, serviços ou mensagens promocionais.

Na concepção de Vaughn et al. (1996), que utilizaram essa técnica em pesquisas na área educacional, a entrevista de grupo focal é uma técnica qualitativa que pode ser utilizada sozinha ou com outras técnicas qualitativas ou quantitativas para aprofundar o conhecimento das necessidades de usuários e clientes.

Para Minayo (2008), as técnicas de grupo mais comuns nas pesquisas qualitativas são os grupos focais e o brainstorming. Trataremos aqui do grupo focal, por esta ser um tipo de entrevista geralmente feita com grupos pequenos e homogêneos(seis a doze pessoas).

. Percebe-se que os autores ao definirem grupo focal generalizam-no, considerando suas características de exposição da palavra falada e/ou escrita, como sendo uma pesquisa 
qualitativa, e que assume verdadeiramente o propósito de coletar informações que fortaleçam e dê veracidade ao que esta sendo pesquisado, quer seja no âmbito educacional, empresarial ou industrial entre outros, pois apresentam características próprias que dinamizam os aspectos a serem observados.

De acordo com Gatti (2012), o processo histórico da técnica de grupo focal tem inicio em 1926 com Bogartus, com atividades desenvolvidas nas Ciências Sociais, com entrevistas grupais. Segue em 1941, também na área de Ciências Sociais com Robert Merton, em 1946, durante a $2^{\mathrm{a}}$ Guerra Mundial, usada por Merton \& Kendall, para investigar o potencial de persuasão da propaganda de guerra para as tropas. Em 1950 na área Marketing com Paul Lazarafeld; 1980 na área da saúde com o objetivo entender as atitudes de doentes, o uso de contraceptivos e para avaliar a interpretação da audiência em relação às mensagens da mídia de modo expressivo. Foi em 1990 que muitos pesquisadores e estudiosos utilizaram essa técnica de coleta de dados como parte integrante de trabalhos e pesquisas para atender aos seus anseios e desejos talvez ainda não realizados pela falta desse contato que trouxe uma verdadeira contribuição para qualificar dados e traçar novas metas a partir do que se apresentavam.

A aplicabilidade do grupo focal se estende a uma variedade de fenômenos que objetiva conhecer a receptividade do grupo sobre um assunto, serviço ou produto, além de diagnosticar preferências, percepções, tendências e hábitos da clientela pesquisada e na área educacional realiza-se levantamento de necessidades voltadas à implementação e implantação de políticas públicas, relacionando as ações e prioridades no contexto escolar, receptividade de métodos, técnicas e recursos diversos.

Segundo Gatti (2012) orienta que para a realização do grupo focal se faz necessário elementos que comporão a equipe nessa técnica, tais como: o moderador que nesse caso, é próprio pesquisador, quatro ou mais colaboradores, para gravação em vídeo, gravação em áudio, registro manual, com o objetivo de garanti com efetividade as falas durante as discussões coletivas, e o grupo que será entrevistado, que é em torno de 6 a 12 pessoas, como recomenda a grande maioria dos autores, que divergem opiniões no que se refere as características dos indivíduos que participarão das discussões, essa deve esta associada aos objetivos da referida pesquisa, por isso uma parte entende que o pesquisador/mediador deve escolher indivíduos com características homogêneas, já outros autores defendem que a composição deve conter pessoas com características heterogêneas, onde a diversificação de sujeitos possibilite um melhor êxito nas discussões, , embora os grupos homogêneos sejam mais defendidos. Deste modo a busca de homogeneidade em algumas características pessoais 
não deve implicar na busca de homogeneidade da percepção do problema. Iervolino; Pelicioni, (2001). Pois nesse caso diversificação de conhecimento do que se debate é que dará a discussão um encaminhamento dinâmico, onde cada sujeito será capaz de refletir diante das divergências apresentadas e talvez refizer seus conceitos.

Para a efetiva realização do evento se faz necessário que o convite aos participantes, que deve ser entregue com certa antecedência, deverá estar associado a um momento de explicação do propósito da discussão, seja um numero maior que o máximo permitido (doze) com o objetivo de garantir o numero mínimo(seis) de frequência. Esse planejamento deve também atender a necessidade de uma agenda que possibilite a participação de todos, assim como o local deve ser de fácil acesso, além de acolhedor, e de preferência com o mínimo de interferências externas.

Assim como toda atividade organizada, segundo Gondim (2002) se faz necessário algumas regras que devem ser expostas em momentos que antecedem tal fato, a saber: Só uma pessoa fala de cada vez; Evitam-se discussões paralelas para que todos participem; Ninguém pode dominar a discussão; Todos têm o direito de dizer o que pensam. Essas regras facilitam para que os registros tenha sua eficácia, além disso, possibilita aos participantes perceber quem são aquelas pessoas que faz parte de uma instituição comum, e que nenhum momento foi dado à oportunidade de refletir a cerca de determinadas questões e talvez inquietações.

O Pesquisador enquanto Moderador deve se aprofundar em pontos específicos, assim como conduzir o grupo de maneira dinâmica e cortes, mesmo quando o ponto já foi suficientemente explorado, estimulando a participação equilibrada, de todos do grupo. A realização do Grupo Focal atende como instrumento de pesquisa, inclusive na pesquisa quantitativa, tem o custo mínimo, além de ágil apresentam dados fies e confiáveis.

O objetivo central do grupo focal é identificar sentimentos, atitudes e ideias dos membros a respeito de um determinado assunto ou tema. Em pesquisas exploratórias, o grupo focal pode ser usado para gerar novas ideias ou hipóteses e estimular o pensamento do pesquisador. Para aqueles que optarem pelo uso do grupo focal, vale lembrar ainda outras limitações desta técnica. Há de se considerar o risco de alguns participantes sentirem-se reprimidos diante da postura grupal, e assim desencorajados de manifestarem opiniões dissidentes. (BACKES. et al, 2011).

Nesse sentido a sutilidade e o sentimento impresso nos participantes serão expostos para reflexão a partir das perguntas e respostas de seus companheiros. O Grupo Focal viabiliza o entendimento coletivo e o ser e estar de cada indivíduo, considerando ainda que permeia de forma latente as trocas de experiências e as reconstruções pautadas na pontuação 
do outro. Não é a toa que os autores em sua maioria defendem a técnica, firmando a veracidade e eficiência de seus dados.

Vejamos a tabela comparativa entre o grupo focal e a entrevista individual, onde estão apresentadas as possíveis discrepâncias que ocorrem quando analisamos as duas técnicas, o que permite perceber as vantagens e desvantagens durante as suas utilizações, podendo associar os objetivos a serem alcançados ao que seria mais viável utilizar:

\section{Quadro 1 - Comparativo entre grupo focal e entrevista individual}

\begin{tabular}{|c|c|}
\hline Grupo focal & Entrevista individual \\
\hline As posições podem sofrer influências & $\begin{array}{l}\text { Não se aplica, em se tratando de um único } \\
\text { entrevistado. }\end{array}$ \\
\hline $\begin{array}{l}\text { A condução do moderador torna-se } \\
\text { mais fácil, por tratar de um } \\
\text { determinado assunto. }\end{array}$ & Pode-se tratar de inúmeros assuntos. \\
\hline $\begin{array}{l}\text { Há um estímulo de novas ideias uma } \\
\text { vez que se faz presente um numero de } \\
\text { pessoas }\end{array}$ & $\begin{array}{l}\text { Não há estímulos externos, normalmente as } \\
\text { entrevistas ocorrem com um número } \\
\text { mínimo de entrevistados. }\end{array}$ \\
\hline $\begin{array}{l}\text { O tempo é contabilizado por } \\
\text { participante em cada pergunta. }\end{array}$ & Normalmente não há tempo estipulado. \\
\hline $\begin{array}{l}\text { Há uma certa dificuldade em encontro } \\
\text { com várias pessoas. }\end{array}$ & $\begin{array}{l}\text { Ficam mais fáceis marcações de entrevistas } \\
\text { individuais. }\end{array}$ \\
\hline $\begin{array}{l}\text { Por se tratar de opiniões diversas, pode } \\
\text { haver conflitos. }\end{array}$ & Passível de conflitos. \\
\hline $\begin{array}{l}\text { O tempo é utilizado a favor, uma vez } \\
\text { que em um menor tempo se obtém } \\
\text { varias informações. }\end{array}$ & $\begin{array}{l}\text { Para obtenção de maiores informações, } \\
\text { precisa de mais tempo. }\end{array}$ \\
\hline $\begin{array}{l}\text { O desconforto em se expor pode } \\
\text { acontecer pela falta de contatos } \\
\text { anteriores com as pessoas. }\end{array}$ & $\begin{array}{l}\text { Dependendo do que se fale, não há } \\
\text { desconforto, pois é um diálogo entre duas } \\
\text { ou mais pessoas. }\end{array}$ \\
\hline
\end{tabular}

Fonte:.Elaborada pela autora

O Grupo Focal, assim como a Entrevista apresentam em sua execução vantagens e desvantagens, e a aplicação de tal técnica esta condicionada a seus objetivos, considerando ainda que durante a entrevista os dados não são comparados a outro, ao contrário do grupo focal que nos faz refletir enquanto o outro expõe, possibilitando repensar e refletir sempre. Por outro lado, se faz necessário associar as propostas durante a aplicação de tal técnica e por fim identificar qual a melhor para que efetivamente alcance êxito na atividade a ser desenvolvida. 


\section{APLICAÇÃO DO GRUPO FOCAL}

A realização do Grupo Focal com alunos do CEEP, foi no dia 03 de dezembro de 2016 (sábado), em uma sala do Centro Educacional Padre Fenelon Costa, localizado na Praça Dr. Joviniano Barreto, no 23/25 no centro de Santo Amaro. Foram distribuídos 15 convites aos estudantes entre os cursos de Comunicação Visual, Gastronomia, Cozinha, Guia de Turismo, Eventos, Administração e Logística, considerando a atuação desses nos projetos escolares, bem como aqueles que diante de pequenos diálogos demonstraram interesse e solicitou participação. Sendo que no dia por motivos inúmeros, compareceram apenas sete estudantes, atendendo a sugestão para realização dessa técnica que seria o mínimo de seis participantes para eficácia das discussões.

As discussões obedeceram a seguinte programação:

\section{Quadro 1 - Programação}

\begin{tabular}{|l|l|}
\hline $7 \mathrm{~h}$ & Organização do Espaço \\
\hline $8 \mathrm{~h}$ & Credenciamento/ Coffe Break \\
\hline $8: 15 \mathrm{~h}$ & Apresentação de Vídeo /Discussão \\
\hline $8: 30 \mathrm{~h}$ & Apresentação do Trabalho em Slides \\
\hline $8: 40 \mathrm{~h}$ & Apresentação dos Estudantes \\
\hline $8: 45$ h & $\begin{array}{l}\text { Pergunta 1- Qual a importância de ser estudante do Ensino Médio? } \\
\text { Resposta: 1 min para cada participante }\end{array}$ \\
\hline $8: 55 \mathrm{~h}$ & $\begin{array}{l}\text { Pergunta 2- Quais as dificuldades que enfrentam na sala de aula e fora dela? } \\
\text { Resposta: 1 min para cada participante }\end{array}$ \\
\hline $9: 05 \mathrm{~h}$ & $\begin{array}{l}\text { Pergunta 3- Como acontece o planejamento de estudos fora da escola? } \\
\text { Resposta: 1 min para cada participante }\end{array}$ \\
\hline $9: 15 \mathrm{~h}$ & $\begin{array}{l}\text { Pergunta 4- Qual a influência familiar na escolha do Curso? } \\
\text { Resposta: 1 min para cada participante }\end{array}$ \\
\hline $9: 25 \mathrm{~h}$ & $\begin{array}{l}\text { Pergunta 5- Quais as contribuições da família para o interesse e permanência } \\
\text { desse aluno na Escola? } \\
\text { Resposta: 1 min para cada participante }\end{array}$ \\
\hline
\end{tabular}


Após a recepção e acomodação dos estudantes que foram dispostos em semicírculo, como indica a programação foi apresentado o objetivo do trabalho e o planejamento do dia, a dinâmica das discussões, finalizando com a apresentação da equipe de trabalho:

1-MODERADOR: LÚCIA HELENA ASSIS (Professora Pesquisadora)

2- SUPORTE DE VÍDEO: PRISCILA MENDES ( Publicitária)

3- SUPORTE DE AUDIO: MANOEL MÁRIO REIS ( Prof. Língua Portuguesa)

4- RELATORA 1: RITA VIRGÍNIA ASSIS ( Prof. de Geografia)

5- RELATORA 2: CLEIDE LOIOLA ( Prof. de Geografia)

6- FOTOGRAFIA: ALOISIO BARBOSA ( Prof. de Educação Física)

7- GRUPO DE FOCO: PARTICIPANTES- DISCENTES

\section{RESULTADOS DA ENTEVISTA COLETIVA}

Foram entrevistados estudantes dos Cursos de Comunicação Visual e Administração, sendo quatro do sexo feminino e três do sexo masculino, com idade entre 16 e 21 anos. Os estudantes em sua maioria residem em Santo Amaro, sendo um único morador de Saubara, (Município próximo de Santo Amaro). Sendo que sete desses residem com seus respectivos pais, e os outros dois residem exclusivamente com suas a mães.

\subsection{VISÃO DO JOVEM ENQUANTO ESTUDANTE DO ENSINO MÉDIO}

Como sendo a última etapa da Educação Básica, e de acordo com a Lei de Diretrizes e Bases da Educação Nacional (LDBEN), o Ensino Médio tem finalidades que estão lá expressas, a saber: assegurar a todos os cidadãos a oportunidade de consolidar e aprofundar os conhecimentos adquiridos no ensino fundamental; aprimorar o educando como pessoa humana, possibilitar o prosseguimento de estudos, garantir a preparação básica para o trabalho e a cidadania e dotar o educando dos instrumentos que lhe permitam continuar aprendendo, tendo em vista o desenvolvimento da compreensão dos fundamentos científicotecnológicos dos processos produtivos (art. 35, incisos I a IV).

Foi apresentado por todos, senão a maioria, a satisfação e valorização de se encontrarem nessa etapa da vida, é unanime, considerando que houve todo um percurso que contribuiu para a tal parcial formação, que os trilhará para a tomada de algumas decisões para 
uma posterior vida adulta que são afloradas nesse momento e as perspectivas são promissoras, indicando que de fato a continuação aos estudos esta no planejamento de todos.

\subsection{DIFICULDADES ENCONTRADAS}

Ao longo da vida estudantil, é notada a diminuição do número de alunos no processo de ascensão ao Ensino Médio. São inúmeras as situações apresentadas que fortalece essa situação tais como: dificuldade de compreensão dos conteúdos, desistência de prosseguir; falta de condições financeiras e organização familiar, que o obriga a trabalhar para garantir o sustento da família; falta de atrativos no ambiente escolar; reprovações sucessivas; desvio de conduta; incentivo a vida fácil, como a venda e uso de drogas; incompreensão e falta de incentivo dos familiares, falta de professores, entre outros itens, que só intensificam a quebra no

prosseguimento aos

estudos.

Essas condições adversas, nos direciona a procurar entender o que de fato vivem esses estudantes. Como sabemos as dificuldades existem, e de acordo com os relatos dos estudantes, de modo gritante podemos destacar como dificuldades encontradas dentro do ambiente escolar, a falta de professor, bem como a falta de ambientes propícios para a realização das aulas práticas, pois se trata de estudantes de Ensino Profissionalizante. Isso remonta que a teoria deve-se associar a prática para a efetiva concretização da profissão, ainda que essa seja a primeira formação com pensamentos rumo ao ensino superior. As dificuldades fora da escola não foram apontadas, pois todos os estudantes se sentem acolhidos no seio familiar, o que lhes dão segurança e força pra prosseguir.

\subsection{PLANEJAMENTO DOS ESTUDOS}

Qual o segredo para garantir noites bem dormidas, cineminha garantido todo fim de semana e boas notas? A resposta é Planejamento. Muitas vezes não admitimos que a falta de vontade de aprender, interfere na concentração e, por conseguinte não se aprende, e o reflexo será nos baixos resultados das avaliações, que se tiverem uma frequência regular nas unidades, por conseguinte teremos uma situação desconfortável a enfrentar: a Recuperação. Logo planejar é o caminho para uma trajetória estudantil de sucesso, que se entende para toda a vida pautada no ato de descrever ou pensar qual será o próximo passo, ao longo dos dias ou anos, com o compromisso de que quando planejamos a realimentação terá mais consistência e 
segurança, na iminência do que podemos apostar assertivamente, prevendo no que pode ser pensado para mais adiante.

O posicionamento dos estudantes foi unânime em esclarecer que de fato não existe um planejamento diário, com o objetivo de fortalecer os estudos desenvolvidos em sala de aula. Acredita-se que essa ação vem ocorrendo ao longo dos anos anteriores e consequentemente a promoção vem ocorrendo, pois caso não fosse às posturas seriam outras. $\mathrm{E}$ as avaliações pontuais ainda são os estímulos para os estudos, ainda que de vésperas, ou em mínimas horas que antecedem sua realização, entendendo que as dificuldades ocorrem para aqueles que possuem uma jornada de trabalho para garanti os sustento familiar, o que não se aplica a maioria. Espera-se que esse comportamento não interfira na vida profissional desses jovens, que vivem seus estudos sem planejar o reforço dos conteúdos e das atividades diárias.

\subsection{FAMÍLIA E A VIDA PROFISSIONAL}

As profissões ao longo dos tempos eram transmitidas de geração em geração, que eventualmente com os avanços da humanidade, em particular na economia, o mercado de trabalho ganhou grandes proporções e hoje deu a possibilidades aos jovens de entender e perceber a diversificação de opções profissionais existentes. São inúmeros os fatores que influenciam na escolha de uma profissão, que pode ser única ou não, vai depender das condições individuais, convicções, valores, situação financeira que se tem juntamente com seus pais e que se quer perpetuar, considerando que está ao seu gosto ou ainda entender que poderá galgar outros caminhos que o tornará satisfeito financeiramente, podendo aliar a vocação as suas necessidades. Nessa etapa, a família é uma das principais responsáveis, quando impõe, direciona ou deixa a critério do jovem na escolha, podemos dizer assim que em algumas situações podem dificultar ou até mesmo ajudar, enfim o histórico familiar será o fator preponderante para tal decisão. A construção da identidade humana se caracteriza por valores morais provenientes das vivências entre indivíduos nos diversos ambientes da sociedade, sendo que é na família, que temos uma convivência diária com nossos pais e construímos valores e preferências, assim, nada mais normal, levarmos em consideração na escolha, essa influência. 
As influências familiares de fato representam os estudantes em seus depoimentos, mas não necessariamente como espelho de pai e mãe, mas pelas situações adversas como atender a uma organização nos negócios da família, ainda que supere suas preferências, tendências e experiências. Considerando ainda que as imposições permeiam as decisões em alguns casos, porem existem as reversões pela defesa de escolha considerando a afinidade. Outros casos expostos são os desvios de escolhas praticados pela Instituição de Ensino, que por estar subsidiada a uma órgão que o gerencia a composição das turmas, é obrigada a oferecer vagas de Cursos que não seria de escolha do estudante, seja pelo Curso possuir o número máximo de alunos ou o contrário, não constituir turmas com Cursos que não apresenta o número de alunos suficientes, por essa razão nesse último, os alunos são remanejados para as turmas com um menor números de alunos, desviando assim os interesses para atender uma demanda que satisfaça o sistema. De modo geral o apoio familiar é significativo e é o que os impulsiona a caminhar rumo ao alcance de seus objetivos.

\subsection{INTERESSE FAMILIAR NOS ESTUDOS}

Em uma maioria os modelos atuais de família, se constituem a imagem de que caberia a escola a responsabilidade em prover a constituição de valores, princípios éticos e padrões de comportamento, tendo como justificativa a dura jornada de trabalho dos pais. Por outro lado constatamos enquanto educadores, que para o êxito do desenvolvimento educacional, a atuação dos familiares torna-se imprescindível para que esses alunos, com a maturidade a caminho, mesmo estando no Ensino Médio precisem de apoio, incentivo e acompanhamento em seus estudos, pois com essa orientação desde do início de sua vida escolar é que o tornará responsável e comprometido com os estudos, pois sua idade identifica que ainda estão sob a responsabilidade de seus pais, logo destacamos para esse público, de que maneira a família demonstra o interesse e permanência desse aluno na Escola.

Os relatos apresentados apontam de fato a participação dos pais ao longo o percurso escolar, sendo fundamental para a criação da responsabilidade e importância dos estudantes. E com esses alunos não seriam diferentes. Os pais em sua maioria sempre optam pelo acompanhamento, ainda que não seja de modo intensivo, normalmente durante ou mais precisamente ao final das unidades letivas, desta forma percebemos que os caminhos poderiam ter outros rumos hoje, se a responsabilidade fosse efetivamente assumida e 
praticada pela família em um tempo regular de acompanhamento junto a unidade escolar de seus dependentes.

\section{CONCLUSÃO}

A presente análise possibilita compreender quais aos anseios de um público, que ao longo da vida diária no âmbito da sala de aula se mostra bastante insatisfeito com o cenário atual que lhes apresenta, fazendo-nos perceber o acaso de estar na escola, sem maiores justificativas aparentes.

Quando se pensa em estudantes de Ensino Médio nos remetemos a uma fase em que juventude pretende concorrer no mercado de trabalho, pleiteando um futuro profissional, ainda que essa primeira etapa não seja decisiva para seu futuro profissional. . Entendendo que esse momento as orientações de caminho a seguir, acontecem no âmbito familiar, bem como na realidade entre colegas e escola, entre outros. Nessa perspectiva cada um desses ambientes, deixam suas influências, e contribui para estruturar um futuro a escolher. Associado ao conhecimento, o homem progride em sua totalidade quando desenvolve atividades que completam sua vida e o torna satisfeito no mundo do trabalho.

Apesar das incoerências de áreas em desacordo coma vontade de alguns alunos, percebemos que em sua maioria pretendem continuar os estudos, e se possível conciliar a profissão técnica com os estudos no ensino superior. E todo esse planejamento está baseado no incentivo familiar, que é a base sólida para essa progressão profissional.

Assim podemos perceber que são inúmeras as influências sofridas por esses jovens, que ajudam a caracteriza-los, e as interferências familiares são marcantes, mas não decisivas, pois trazem consigo também a formação de caráter que o constitui singular diante da sociedade que o transforma a partir das necessidades que são apresentadas ao longo de seu amadurecimento.

\section{REFERÊNCIAS BIBLIOGRAFICAS}

BACKES, Dirce Stein. et al. Grupo focal como técnica de coleta e análise de dados em pesquisas qualitativas. Revista Mundo da Saúde, São Paulo, v. 35, n. 4, p. 438-442. 2011. Disponível em: <http://bvsms.saude.gov.br/bvs/artigos/grupo_focal_como_tecnica_coleta_ analise_dados_pesquisa_qualitativa.pdf $>$. Acesso em 20 jul. 2014. 
BRASIL. Ministério da Educação. Secretaria da Educação Básica. Lei de Diretrizes e Bases da Educação Nacional. p. 18. Brasília, 2005.

CAPLAN, S. Using focus group methodology for ergonomic design. Ergonomics, v. 33, n. 5, p. 527-33, 1990.

GATTI, Bernadete Angelina. Grupo Focal na pesquisa em Ciências Sociais e Humanas. Brasília, 2012.

GONDIM, Sônia Maria. Grupos focais como técnica de investigaçãoqualitativa: desafios metodológicos. Revista Paidéia, v.12, n.24, 2002

IERVOLINO, S.A.; PELICIONI, M.C.F. A utilização do grupo focal como metodologia qualitativa na promoção da saúde. Rev Esc Enf USP, v. 35, n.2, p.115-21, jun, 2001.

MINAYO, Maria Cecília de Souza. O desafio do conhecimento. 11 ed. São Paulo: Hucitec, 2008.

VAUGHN, S. et al. Focus group interviews in education and psychology. Thousand Oaks, CA: Sage Publications, 1996. 